\title{
Virulence characteristics of five new Campylobacter jejuni chicken isolates
}

\author{
Lavinia Stef ${ }^{1}$, Ada Cean ${ }^{1}$, Aida Vasile ${ }^{3}$, Calin Julean ${ }^{1}$, Dan Drinceanu ${ }^{1}$ and Nicolae Corcionivoschi ${ }^{1,2^{*}}$
}

\begin{abstract}
Campylobacter enteritis has emerged as one of the most common forms of human diarrheal illness. In this study we have investigated the virulence potential of five new C. jejuni chicken isolates (RO14, RO19, RO24, RO29 and RO37) originated from private households in the rural regions of Banat and Transylvania in Romania. Following isolation and in vitro virulence assay, on HCT-8 cells, our results show that all the C. jejuni chicken isolates overcome the virulence abilities of the highly virulent strain C. jejuni 81-176. Motility, an important virulence factor was significantly improved in all the new chicken isolates. The ability to survive to the antimicrobial activity of the human serum, to resist to the violent attack of bile acids and to survive in the presence of synthetic antibiotics was increased in all the chicken isolates. However, these were statistically significant only for isolates RO29 and RO37. In conclusion our study shows, based on invasiveness and motility, and also on the data provided by the serum and bile resistance experiments that all the new chicken isolates are able to infect human cells, in vitro, and could potentially represent a health hazard for humans.
\end{abstract}

\section{Introduction}

Campylobacter jejuni is a leading cause of enteric illness in many the western world, developing countries. Within European Union there were 198000 confirmed cases of campylobacteriosis in 2009 [1]. Campylobacter jejuni belongs to the group of thermo-tolerant bacteria being the most frequent cause of gastrointestinal diseases in humans. Campylobacter enteritis is considered to be a food-bourne disese rather than food poisoning, with infections being derived from a range of foods and also water-based environmental sources. Asymptomatic infections, watery and bloody diarrhea have been reported in humans. Epidemiological studies have shown that human Campylobacter infection may vary according to geographical area and even with age [2].

Campylobacter jejuni is present in the intestinal tract of a wide variety of wild and domestic animals. The contamination of the retail products occurs by de-feathering, evisceration and dipping during slaughtering [3]. In chickens,

\footnotetext{
* Correspondence: nicolae.corcionivoschi@ucd.ie

'School of Animal Sciences and Biotechnology, Banat University of Agricultural Sciences and Veterinary Medicine - King Michael I of Romania, Calea Aradului nr. 119, Timisoara, Romania

${ }^{2}$ National Children Research Centre, Our Lady's Hospital for Sick Children, Crumlin Road, Dublin 12, Ireland

Full list of author information is available at the end of the article
}

C. jejuni colonizes the mucus overlying the epithelial cells primarily in the ceca and the small intestine but may also be recovered from elsewhere in the gut and from the spleen and liver [4]. Although C. jejuni is not likely to grow or survive well in foods often between $40-85 \%$ of retail poultry carcasess are C. jejuni postive [5]. Furthermore recent studies suggest that ingestion of a small number of C. jejuni organisms will result in human illness [6]. Little is known about the incidence of $C$. jejuni infections in Estern Europe and in particular in Romania. Once the Eastern European countries joined European Union it became of extreme importance for the food industry to assess and investigate the field situation in regards to the existent $C$. jejuni strains and to study their potential virulence to humans.

The origin of these strains seems to be important for their virulence and it was reported that there is a correlation between pathogenicity and geographic area of origin of Campylobacter strains [7]. Several virulence factors are considered to be important for $C$. jejuni induced enteritis, such as adhesion and invasion of epithelial cells [8], motility [9], serum resistance [10] and resistance to bile salts $[11,12]$. Poultry meat is an important reservoir and source of $C$. jejuni infection in Romania but little is known in regards to the virulence of $C$. jejuni strains currently present within the poultry farms. In this study we have 
investigated these virulence characteristics by comparing in vitro, the five chicken isolates from Banat-Transylvania region of Romania with the $C$. jejuni 81-176 human isolate which today is the model strain of choice for invasiveness and virulence in the literature.

\section{Material and methods}

\section{Bacterial strains and growth conditions}

C. jejuni strains $(\mathrm{n}=5)$ were isolated from cloacal swabs of broilers, conventionally housed raised in small family farms within the regions of Banat and Transylvania in Romania, in 2013. These strains have been named RO14, RO19, RO24, RO29 and RO37. C. jejuni 81-176 was also used as control strain in the virulence experiments. All strains used in this study were stored at $-80^{\circ} \mathrm{C}$ in Mueller-Hinton broth containing 20\% (v/v) glycerol until required. Strains had been minimally passaged in vitro before storage and subsequent testing. When required, bacteria were inoculated on Mueller-Hinton agar containing selective Skirrow's antibiotics (Oxoid) and grown under microaerobic conditions $\left(5 \% \mathrm{CO}_{2}, 5 \% \mathrm{O}_{2}\right.$, $90 \% \mathrm{~N}_{2}$ ) at $42^{\circ} \mathrm{C}$. After 24 h growth, a loopful of bacteria was inoculated into biphasic media containing MuellerHinton agar and RPMI 1640 tissue culture media supplemented with $10 \%$ fetal calf serum. This was cultured for $18 \mathrm{~h}$ at $42^{\circ} \mathrm{C}$ microaerobically for invasion assays. These conditions were determined in preliminary studies as optimum growth conditions for the invasion assay. The isolation of strains has been done accordingly to the legislation in place (Law 471/2002 and government ordinance 37/2002) under the supervision of National Sanitary Veterinary Agency. The ethics committee of Banat University of Agricultural Sciences and Veterinary Medicine - King Michael I of Romania, approved this work.

\section{Bacterial isolation and identification}

Biological material: Chicken broilers from 6 intensive breeding facilities from the West part of Romania. From each breeding unit 3 animals were taken for study, a total of 18 animals were used for this study. Sample collection: Cloaca swabs were recovered using a sterile cotton swab, after collection the sample was sealed into a sterile plastic tube and transported to the laboratory. The fecal samples were collected from cecum directly into the laboratory, under sterile conditions, for this the cecum was recovered from the animals into a sterile petri dish and transported in the laboratory. Within 1520 minutes from collection the samples were processed. Bacterial isolation: The sample from cloaca swab was dissolved into $900 \mu \mathrm{l}$ sterile water, after that serial dilutions were performed until $10^{5}$ and $100 \mu \mathrm{l}$ of each dilution was plated on to $9.5 \mathrm{~cm}$ Petri dish with Muller Hinton Agar media (CM0337, Thermo scientific), prepared according to the producer instructions. For the feces sample approximately $100 \mu \mathrm{l}$ of the cecum content was diluted into $900 \mu \mathrm{l}$ of sterile water, and serial dilutions was performed from this. Dilutions from $10^{2}$ to $10^{6}$ were plated on the same media as swab samples. After 72-96 hours of incubation at $37^{\circ} \mathrm{C}$, in microaerophilic conditions, colonies with Campylobacter sp. aspect were picked and inseminated on Muller-Hinton agar media supplemented with campylobacter selective supplement (Skirrow, SR0069, Thermo scientific). All plates were incubated at $37^{\circ} \mathrm{C}$ in microaerophilic conditions using CampyGen AGS (CN0025A, Thermo scientific). The identification of the isolates was performed with conventional (sodium hippurate hydrolysis and commercial identification system (Api CAMPY system, bioMerieux, France).

\section{Infection assays}

The gentamicin protection assay was used to test the ability of $C$. jejuni chicken isolates by comparison with the highly virulent strain $C$. jejuni 81-176 to adhere and invade human instestinal epithelial cells [10]. Briefly, HCT-8 cells were grown (60\% confluence) for 15 to $18 \mathrm{~h}$ in six-well tissue culture plates at a concentration of $1 \times$ $10^{5}$ cells per well. Plate grown $C$. jejuni 81-176 wild type and $C$. jejuni chicken isolates were washed and resuspended in tissue culture medium at an $\mathrm{OD}_{600}$ of 0.4. The HCT-8 cells were washed with PBS, and $2 \mathrm{ml}$ of fresh culture medium was added to each well. Bacteria were added to give a multiplicity of infection of 10 . Tissue culture plates were centrifuged at $250 \times \mathrm{g}$ for $5 \mathrm{~min}$ and incubated for $3 \mathrm{~h}$ at $37^{\circ} \mathrm{C}$ in $10 \% \mathrm{CO}_{2}$. To quantify the number of cell-associated bacteria, infected monolayers were washed at least three times with PBS and treated with $0.1 \%$ Triton $\mathrm{X}-100$ in $\mathrm{PBS}$ at $37^{\circ} \mathrm{C}$ for $30 \mathrm{mi}-$ nutes. Tenfold dilutions of each well were plated onto the appropriate agar and colonies enumerated after 3 days of incubation. To quantify the number of bacteria that invaded HCT-8 cells, the infected monolayers were washed with PBS and tissue culture medium $(2 \mathrm{ml})$ containing gentamicin $(400 \mu \mathrm{g} / \mathrm{ml})$ was added to half the wells, and medium with no antibiotic was added to the remaining wells. The tissue culture plates were then incubated for a further $2 \mathrm{~h}$ at $37^{\circ} \mathrm{C}$ and washed with PBS. HCT- 8 cells were lysed by the addition of $100 \mu \mathrm{l}$ of $0.1 \%$ Triton X-100 in PBS and incubated for 10 to $15 \mathrm{~min}$ at $37^{\circ} \mathrm{C}$. Tenfold dilutions of the contents of each well were plated on Mueller Hinton agar and colonies were enumerated after 3 days of incubation. Invasion efficiency was calculated as the average of the total number of CFU/total initial inoculum. C. jejuni 81-176 passaged in RPMI 1640 (without cells) was also tested for the ability to adhere to and invade HCT-8 cells. The experiments were conducted on three separate occasions. Results for a representative experiment are presented. The error 
bars represent standard deviations for three separate wells.. The significance of differences in adhesion and invasion between samples was determined using the Student $t$ test. A P value of $<0.05$ was defined as significant.

\section{Motility assays}

The motility experiments were done according with the method previously described [13]. Five microliters of culture was inoculated into the center of the Mueller Hinton agar plates $(0.4 \%$ agar), and the diameter of the resulting swarms was measured the next day, following incubation for 24 hours at $42^{\circ} \mathrm{C}$ in microaerbic conditions. Motility was characterized like an area of growth around the central point of the plate and measured in millimeters.

\section{Serum resistance}

The sensitivity of bacteria to human serum (Invitrogen) was measured. C.jejuni 81-176 wild type and the chicken isolates ( $\mathrm{RO} 14, \mathrm{RO} 19, \mathrm{RO} 24, \mathrm{RO} 29$ and RO37) were plate-grown and resuspended in fresh tissue culture medium (RPMI 1640) to give an $\mathrm{OD}_{600}$ of 0.1 . Five microliters of bacterial suspension was added to duplicate wells of a six-well plate containing $800 \mu \mathrm{l}$ of MuellerHinton broth and $200 \mu \mathrm{l}$ of active pooled human serum or to separate wells containing $800 \mu \mathrm{l}$ of Mueller-Hinton broth and $200 \mu$ l heat-inactivated human serum. The plates were incubated for $1 \mathrm{~h}$ at $37^{\circ} \mathrm{C}$ under microaerobic conditions. Bacteria from each well were diluted 10fold and plated on dry Mueller-Hinton agar plates. The plates were incubated at $37^{\circ} \mathrm{C}$ under microaerobic conditions. Colony counts were performed after an incubation time of 2 days. All assays were conducted in triplicate and repeated independently three times.

\section{Resistance to bile salts}

$\mathrm{MH}$ broth was supplemented with $4.0 \%$ (wt/vol) bile salts and $50 \mathrm{~mL}$ of media was transferred into $100 \mathrm{ml}$ bottles for each treatment for the chicken isolates and $C$. jejuni 81-176. The medium was then autoclaved and, once cooled, $1 \mathrm{ml}$ of either chicken isolates or $C$. jejuni 81-176 cells were transferred to each bottle. This experiment was carried out in triplicate. The bottles were left in optimum growth conditions for 24 hours after which $20 \mu \mathrm{l}$ was removed and diluted with $100 \mu \mathrm{l}$ of water. The series of dilutions were then plated as before and a second set of samples were obtained and diluted after a further 18 hours. Viable cell counts for each plate were determined at the end of the incubation period.

\section{Antimicrobial resistance}

Six antibiotics (nalidixic acid, ciprofloxacin, erythromycin, ampicillin, amoxicillin-clavulanic acid and gentamicin) were tested using the disk E test (Solna, Sweeden). The bacterial inoculum was adjusted to 0.5 McFarland standard turbidity and Mueller-Hinton agar supplemented were used. Bacterial suspension was inoculated in MuellerHinton agar Petri dishes. When the plates were dry, six antimicrobial disks were applied per plate and incubated over night in microaerobic conditions at $37^{\circ} \mathrm{C}$.

\section{Statistical analysis}

Experiments were conducted on at least three separate occasions in triplicates. Results are presented as the means \pm standard deviations (error bars) of three replicate experiments. Graphs were drawn using Prism, and the unpaired Student $t$ test was used to estimate statistical significance. A $P$ value of $<0.05$ was considered significant.

\section{Results}

Adhesion and invasiveness of $C$. jejuni strains isolated from poultry

The virulence of the five chicken isolates (RO14, RO19, RO24, RO29 and RO37) was tested using HCT-8 cells and adhesion/invasion were compared with the model strain C. jejuni 81-176, to correct for experimental variation. Invasiveness varied considerably between the investigated strains, as is shown in Figure 1A (adhesion) and $\mathrm{B}$ (invasion). Following gentamicin protection assay we have shown that the total adhesion of the chicken isolates is significantly increased compared to the total adhesion of $C$. jejuni 81-176. From the distribution profile obtained the most significant increase in adhesion was recorded for isolate RO37. Normally adhesion levels are not always associated with an increase in the number of bacteria that penetrate the epithelial cells. However, for the C. jejuni chicken isolates described in this study this was not the case as higher levels of internalization were found in all isolated strains. Similarly, to the adhesion results, the chicken isolate RO37 had the highest internalization levels compared to C. jejuni 81-176.

\section{Motility of poultry isolated $C$. jejuni strains}

Motility was previously described as an important virulence factor in C. jejuni described [9]. Based on our results, showing improved adhesion and invasion of all the chicken isolates, next we have investigated their motility. As expected all these new strains showed increased motility compared to the control strain C. jejuni 81-176 as judged by the increased migration in semisolid agar (Figure 2), which correlates with their increase in virulence. Statistically all the increases in motility were significant but similarly as for adhesion/invasion the most significant increase was observed for strain RO37 ( $p<0.0001$ ).

\section{Resistance to human serum}

The ability of $C$. jejuni to cause systemic infection in imuncompromised hosts it was suggested to be related 


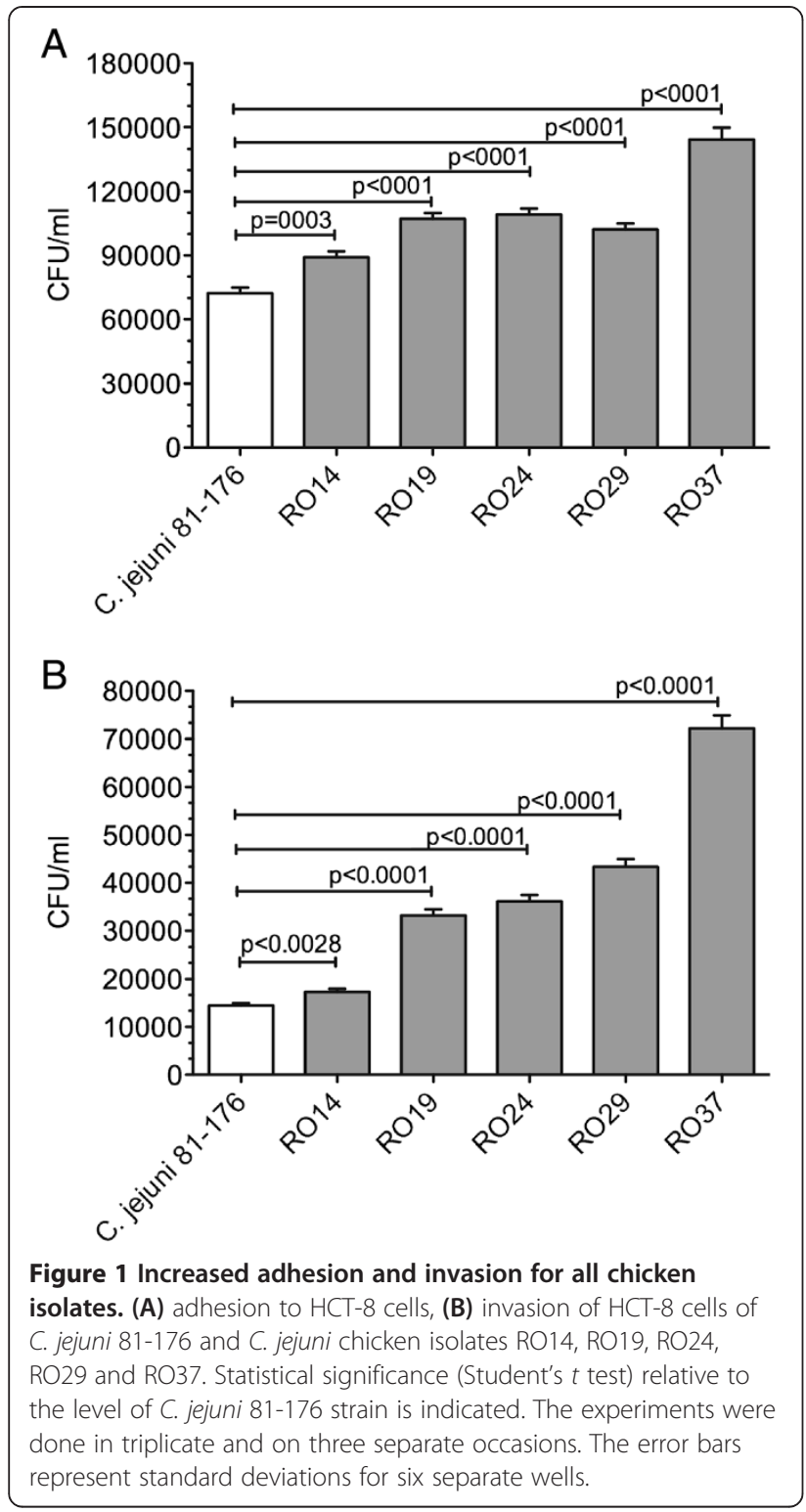

to the increase in resistance to the bactericidal activity present in the serum of these patients [14]. Suerly, this will not be the case with the human serum (Invitrogen) and we have investigated the serum survival rate of these newly chicken isolated strains. As shown in Figure 3 the isolates RO14 ( $\mathrm{p}=0.25), \mathrm{RO} 19(\mathrm{p}=0.15)$ and RO24 ( $\mathrm{p}=$ 0.17 ) had a better rate of survival in human serum but not statistically significant. However, the isolates RO29 $(\mathrm{p}=0.03)$ and RO37 ( $\mathrm{p}=0.0001)$ had a significantly incresed serum survival rate (Figure 3 ) compared to the control strain C. jejuni 81-176.

\section{Resistance to bile salts}

In order to fulfill its pathogenicity, in vivo, C. jejuni must resist the deleterious actions of bile in order to survive in the human gastrointestinal tract. This experiment

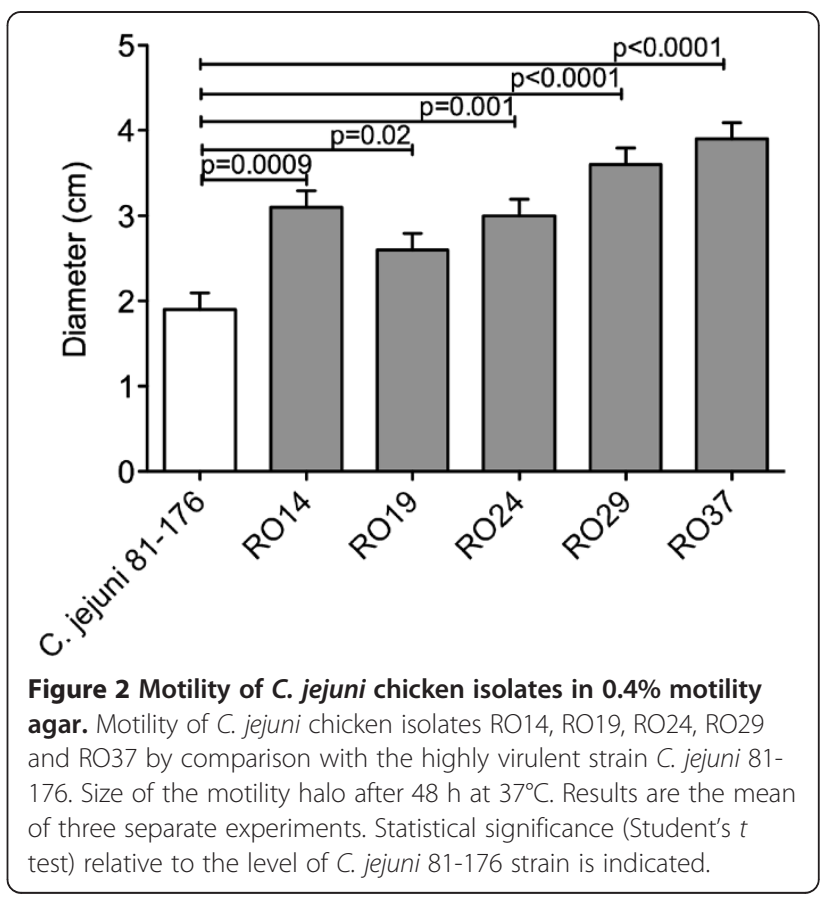

aimed to observe any differences between the response of C. jejuni 81-176 and chickens isolates to elevated levels of bile salts in the media and, as a result, speculate on their behaviour within their normal habitat of the intestine. The chicken isolates RO14, RO19 and RO24 had a percentage of survival similar to $C$. jejuni $81-176$ (Figure 4). The most

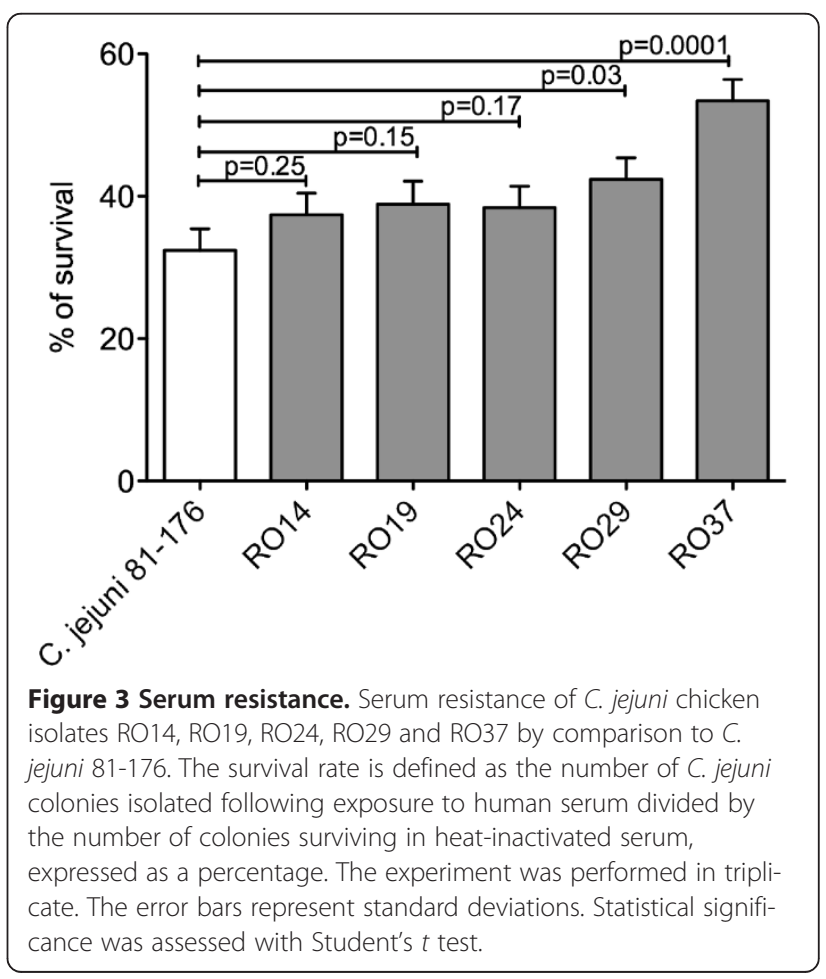


significant increase in survival was observed for the chicken isolate RO29 where the increase was over 30\% $(\mathrm{p}<0.0001)$. The chickens isolate RO37, which has been proven also to be the most virulent (Figure 1B) an increase of in bile resistance of $15 \%$ was detected.

\section{Antimicrobial resistance}

For each $C$. jejuni isolate antibiotic inhibition zones to the various antibiotics were recorded and compared to the resistance of $C$. jejuni 81-176 control strain. The antibiotic profiles of the $C$. jejuni poultry isolates were different to the profiles of $C$. jejuni 81-176 control strain which shwed restitace only to gentamicin (Table 1). Only two of the chicken isolates were senzitive to nalidixic acid (RO19 and RO24). The resistance to erythromycin and ampicillin was detected for all the chicken isolates but interestingly not for the control strain. For ciprofloxacin and amixicillin-clavulinic acid the resistance profiles of the chicken isolates matched the profile of $C$. jejuni 81-176, lack of resistance being detected for all of them. Resistance to gentamicin was detected for RO19, RO29 and RO37 chicken isolates and also for the control strain C. jejuni 81-176.

\section{Discussions}

In 2010 the European Centre for Disease Prevention and Control (EFSA) reported that campylobacteriosis is still the most common zoonosis in the European Union (EU) [15]. In the past ten years a total of 13 new countries in

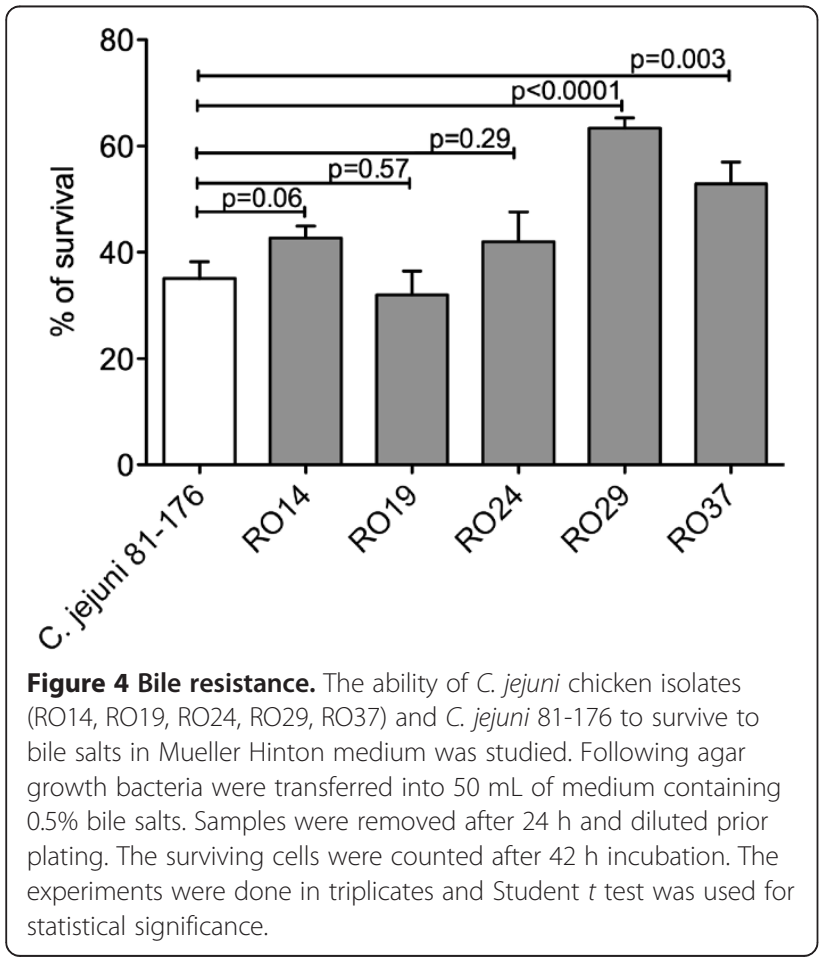

Eastern Europe joined the EU and currently very little is known in regards to the virulence of $C$. jejuni strains currently present in those areas. In humans the most common cause of campylobacter enteritis is caused by C. jejuni which commonly colonizes the intestinal tract of chickens [16]. It is now recognized that in some countries in Eastern Europe, especially in suburban areas, much of the population grow chicken broilers for their own consumption. Therefore our study focused on the isolation and investigation of the virulence characteristics of $C$. jejuni strains isolated from households in rural areas in the regions of Banat and Transylvania of Romania.

An essential feature in the development of an infectious disease is the initial transport of the bacterial pathogen to the host. In chickens, $C$. jejuni will only colonize the mucosa without entering the epithelial cells. The success in colonization will depend on the ability of bacteria to compete successfully with the host's normal microbiota for essential nutrients. However, in the human gut $C$. jejuni will have to will have to not only to perform colonization but also internalization in order to cause infection. In order to achieve this the pathogen will have fulfill few conditions for an efficient infection that includes: high motility [17], to out rule the detrimental effects of the bile [18], to express efficiently adhesion molecules $[19,20]$ and if the infection becomes systemic to survive the antimicrobial effect of the human serum [21].

The mechanisms by which Campylobacter species cause diarrhea and possible subsequent sequelae are not well defined. Invasion and adhesion are generally an important pathogenic factor and it was reported for clinical and non-clinical isolates [22,23]. In our experiments all the chicken isolates were significantly more adherent and invasive compared to the control strain C. jejuni 81176. This finding is consistent with previous reported data showing that chicken isolates are more or at least as invasive as human isolates [11]. Studies with isolated primary cells from chickens showed that $C$. jejuni was able to invade chicken cells [24] and that invasion is largely dependent on strain isolates.

Motility plays and important role in Campylobacter colonization, since the organism has to penetrate mucus in order to adhere to and invade surface epithelial cells. In our study the motility of the five chicken isolates, found to have different virulence potential following examination on motility agar. The role of motility has been previously demonstrated in several animal models [25] and also on human volunteer experiments [26]. We have also shown previously that diminished motility results in reduced ability of $C$. jejuni 81-176 to infect human epithelial cells [13]. The increased motility of the new chicken isolates will be of great importance for 
Table 1 Antimicrobial resistance rates of $C$. jejuni isolated from poultry

\begin{tabular}{|c|c|c|c|c|c|c|}
\hline Specie & Nalidixic acid & Ciprofloxacin & Erythromycin & Ampicillin & Amoxicilin-clavulanic acid & Gentamicin \\
\hline C. jejuni 81-176 & - & - & - & - & - & + \\
\hline $\mathrm{RO} 14$ & + & - & + & + & - & - \\
\hline RO19 & - & - & + & + & - & + \\
\hline $\mathrm{RO} 24$ & - & - & + & + & - & - \\
\hline $\mathrm{RO} 29$ & + & - & + & + & - & + \\
\hline $\mathrm{RO} 37$ & + & - & + & + & - & + \\
\hline
\end{tabular}

bacterial host interactions during infection and will impact on their the ability to cause disease.

When systemic $C$. jejuni occurs in an immunocompromised individual the bacterium will have to overcome the antimicrobial activity of the human serum. This antibacterial activity of a serum component is an important innate defense against bacteria within the vascular compartment. Using fresly pooled human serum we show that only two of the chicken isolates (RO29 and RO37) were significantly more resistant compared to $C$. jejuni 81-176. The resistance to human serum, of these two strains, might arise from unique surface charcateristics allowing them to evade the bactericidal effect of serum complements. How and why these new isolates are more virulent requires investigation of important virulence factors including capsule polysaccharide (CPS). The amount of CPS was shown to be important for the survival of $C$. jejuni to human serum [27]. One important feature involved in serum resistance reffers to the protein structure of the S-layer which is also involved in mediating bacterial resistance to human serum. These proteins will confer resistance to complement-mediated killing by using opsonic antibodies directed against the S-layer [28].

Little is known on the bile tolerance of Gram-negative bacteria, but it is belived that they are more resistant to bile than Gram-positive bacteria. An adaptation that is vital to the survival of Campylobacter in the gut and, hence, its success in causing infection, is its ability to withstand the presence of bile salts in the surrounding environment. Such an adaptation will serve as a competitive advantage over other bacteria colonising the gut. The volume of the bile salt pool in man has been estimated as either $4 \mathrm{~g}$ or $7.6 \mathrm{mmol}$ was identified as $7.6 \pm$ $0.9 \mathrm{mmol}$, which is secreted and reabsorbed at least twice during the digestion of a single meal [29]. Our results show that, at least for two of the chicken isolates (RO29 and RO37) their survival rates in the presence of bile acids were significantly higher when compared to the survival rate of $C$. jejuni 81-176. This increase in survival to the bile acids could have a positive impact on the pathogenic abilities of this two strains and corelate to the other virulence traits here identified.
In most cases Campylobacter infections are acute and self-limited in nature and will not require antibiotic treatment, unless infections occur in immunocompromised patients. Unfortunately, not all the laboratories will routinely perform antimicrobial testing of new C. jejuni isolates. In our experiments the resistance to erythromycin was very high in all $C$. jejuni chicken isolates similarly to what was previously reported in the literature [30]. The resistance to erythromycin, in the new $C$. jejuni chicken isolates, was not acquired via plasmid conjugation since the erythromycin resistance is unrelated to the presence of plasmid DNA and therefore is considered to be chromosomally mediated [31]. The production of beta-lactamases in bacteria is associated with resistance to ampicillin and in our experiments all the C. jejuni chicken isolates are highly resistant to ampicillin.

However, when an antibiotic resistant to beta-lactamases is used (combination of amoxicillin and clavulanic acid), all the new $C$. jejuni chicken isolates were not able to survive.

In conclusion, we have shown that $C$. jejuni chicken isolates exhibit a range of invasion phenotypes with hyper invasiveness being more frequently observed among C. jejuni chicken isolates. However, extrapolating these results to the host it is premature at this stage because $C$. jejuni infection is highly dependent on the physiological and immunological condition of the host.

\section{Competing interests}

The authors declare that they have no competing interests.

\section{Authors' contributions}

LS, NC and DD designed the study; AT, CJ performed experiments; NC wrote the paper. All authors read and approved the final manuscript.

\section{Acknowledgements}

This work was supported by a grant of the Romanian National Authority for Scientific Research, CNCS-UEFISCDI, project number PN-II-RU-TE-2012-3-0092 and The National Children Research Centre, Crumlin, Dublin 12, Ireland.

Author details

${ }^{1}$ School of Animal Sciences and Biotechnology, Banat University of Agricultural Sciences and Veterinary Medicine - King Michael I of Romania, Calea Aradului nr. 119, Timisoara, Romania. ${ }^{2}$ National Children Research Centre, Our Lady's Hospital for Sick Children, Crumlin Road, Dublin 12, Ireland. ${ }^{3}$ Dunarea de Jos University, Galati, Romania. 
Received: 7 November 2013 Accepted: 9 December 2013

Published: 13 December 2013

\section{References}

1. Wagenaar JA, French NP, Havelaar AH: Preventing campylobacter at the source: Why is it so difficult? Clin Infect Dis 2013, 57(11):1600-1606. Dec

2. Fedoroff NV, Battisti DS, Beachy RN, Cooper PJ, Fischhoff DA, Hodges CN, Knauf VC, Lobell D, Mazur BJ, Molden D, et al: Radically rethinking agriculture for the 21st century. Science 2010, 327:833-834.

3. Di Giannatale E, Prencipe V, Colangeli P, Alessiani A, Barco L, Staffolani M, Tagliabue S, Grattarola C, Cerrone A, Costa A, et al: Prevalence of thermotolerant Campylobacter in broiler flocks and broiler carcasses in Italy. Vet Ital 2010, 46:405-423.

4. Lamb-Rosteski JM, Kalischuk LD, Inglis GD, Buret AG: Epidermal gr\{MalikKale, 2008 \#1770\}owth factor inhibits Campylobacter jejuni-induced claudin-4 disruption, loss of epithelial barrier function, and Escherichia coli translocation. Inf Immun 2008, 76:3390-3398.

5. Arumugaswamy RK, Proudford RW, Eyles MJ: The response of Campylobacter jejuni and Campylobacter coli in the Sydney rock oyster (Crassostrea commercialis), during depuration and storage. Int J Food Microbiol 1988, 7:173-183.

6. Janssen R, Krogfelt KA, Cawthraw SA, van Pelt W, Wagenaar JA, Owen RJ: Host-pathogen interactions in Campylobacter infections: the host perspective. Clin Microbiol Rev 2008, 21:505-518.

7. Bessell PR, Matthews L, Smith-Palmer A, Rotariu O, Strachan NJ, Forbes KJ, Cowden JM, Reid SW, Innocent GT: Geographic determinants of reported human Campylobacter infections in Scotland. BMC public health 2010, 10:423.

8. Bacon DJ, Szymanski CM, Burr DH, Silver RP, Alm RA, Guerry P: A phasevariable capsule is involved in virulence of Campylobacter jejuni 81-176. Mol Microbiol 2001, 40:769-777

9. Szymanski CM, King M, Haardt M, Armstrong GD: Campylobacter jejun motility and invasion of Caco-2 cells. Infect Immun 1995, 63:4295-4300

10. Corcionivoschi N, Clyne M, Lyons A, Elmi A, Gundogdu O, Wren BW, Dorrel $\mathrm{N}$, Karlyshev AV, Bourke B: Campylobacter jejuni cocultured with epithelial cells reduces surface capsular polysaccharide expression. Infect Immun 2009, 77:1959-1967.

11. Van Deun K, Haesebrouck F, Heyndrickx M, Favoreel H, Dewulf J, Ceelen L, Dumez L, Messens W, Leleu S, Van Immerseel F, et al: Virulence properties of Campylobacter jejuni isolates of poultry and human origin. J Med Microbiol 2007, 56:1284-1289.

12. Malik-Kale P, Parker CT, Konkel ME: Culture of Campylobacter jejuni with sodium deoxycholate induces virulence gene expression. J Bacterio/ 2008, 190:2286-2297.

13. Corcionivoschi N, Alvarez LA, Sharp TH, Strengert M, Alemka A, Mantell J, Verkade $P$, Knaus UG, Bourke B: Mucosal reactive oxygen species decrease virulence by disrupting Campylobacter jejuni phosphotyrosine signaling. Cell Host Microbe 2012, 12:47-59.

14. Blaser MJ, Smith PF, Kohler PF: Susceptibility of Campylobacter isolates to the bactericidal activity of human serum. J Infect Dis 1985, 151:227-235.

15. Lahuerta A, Helwigh B, Makela P: Zoonoses in Europe: distribution and trends - the EFSA-ECDC Community Summary Report 2008. Euro Surveill 2010, 15:19476.

16. Hermans D, Van Deun K, Martel A, Van Immerseel F, Messens W, Heyndrickx M, Haesebrouck F, Pasmans F: Colonization factors of Campylobacter jejuni in the chicken gut. Vet Res 2011, 42:82.

17. Wassenaar TM, van der Zeijst BA, Ayling R, Newell DG: Colonization of chicks by motility mutants of Campylobacter jejuni demonstrates the importance of flagellin A expression. J Gen Microbiol 1993, 139(Pt 6):1171-1175.

18. Takatsu M, Ichiyama S, Nada T, linuma Y, Toyoda H, Fukuda Y, Nakashima N: Campylobacter fetus subsp. fetus cholecystitis in a patient with advanced hepatocellular carcinoma. Scand J Infect Dis 1997, 29:197-198.

19. Flanagan RC, Neal-McKinney JM, Dhillon AS, Miller WG, Konkel ME: Examination of Campylobacter jejuni putative adhesins leads to the identification of a new protein, designated FlpA, required for chicken colonization. Infect Immun 2009, 77:2399-2407.

20. Konkel ME, Christensen JE, Dhillon AS, Lane AB, Hare-Sanford R, Schaberg DM, Larson CL: Campylobacter jejuni strains compete for colonization in broiler chicks. Appl Environ Microbiol 2007, 73:2297-2305.
21. Guerry P, Ewing CP, Hickey TE, Prendergast MM, Moran AP: Sialylation of lipooligosaccharide cores affects immunogenicity and serum resistance of Campylobacter jejuni. Infect Immun 2000, 68:6656-6662.

22. Konkel ME, Joens LA: Adhesion to and invasion of HEp-2 cells by Campylobacter spp. Infect Immun 1989, 57:2984-2990.

23. Konkel ME, Monteville MR, Rivera-Amill V, Joens LA: The pathogenesis of Campylobacter jejuni-mediated enteritis. Curr Issues Intest Microbiol 2001, 2:55-71.

24. Byrne CM, Clyne M, Bourke B: Campylobacter jejuni adhere to and invade chicken intestinal epithelial cells in vitro. Microbiology 2007, 153:561-569.

25. Pavlovskis OR, Rollins DM, Haberberger RL Jr, Green AE, Habash L, Strocko S, Walker RI: Significance of flagella in colonization resistance of rabbits immunized with Campylobacter spp. Infect Immun 1991, 59:2259-2264.

26. Black RE, Levine MM, Clements ML, Hughes TP, Blaser MJ: Experimental Campylobacter jejuni infection in humans. J Infect Dis 1988, 157:472-479.

27. Maue AC, Mohawk KL, Giles DK, Poly F, Ewing CP, Jiao Y, Lee G, Ma Z, Monteiro MA, Hill CL, et al: The polysaccharide capsule of Campylobacter jejuni modulates the host immune response. Infect Immun 2013, 81:665-672.

28. Thompson SA: Campylobacter surface-layers (S-layers) and immune evasion. Ann Periodontol 2002, 7:43-53.

29. Jazrawi RP, Bridges C, Joseph AE, Northfield TC: Effects of artificial depletion of the bile acid pool in man. Gut 1986, 27:771-777.

30. Marinou I, Bersimis S, loannidis A, Nicolaou C, Mitroussia-Ziouva A, Legakis $\mathrm{NJ}$, Chatzipanagiotou S: Identification and antimicrobial resistance of campylobacter species isolated from animal sources. Front Microbiol 2012 3:58.

31. Taylor DE, Courvalin P: Mechanisms of antibiotic resistance in Campylobacter species. Antimicrob Agents Chemother 1988, 32:1107-1112.

doi:10.1186/1757-4749-5-41

Cite this article as: Stef et al:: Virulence characteristics of five new

Campylobacter jejuni chicken isolates. Gut Pathogens 2013 5:41.

\section{Submit your next manuscript to BioMed Central and take full advantage of:}

- Convenient online submission

- Thorough peer review

- No space constraints or color figure charges

- Immediate publication on acceptance

- Inclusion in PubMed, CAS, Scopus and Google Scholar

- Research which is freely available for redistribution

Submit your manuscript at www.biomedcentral.com/submit
C) Biomed Central 